\title{
クラストを有する軟弱地盤の支持力について ON THE BEARING CAPACITY OF SOFT CLAY WITH A SURFACE CRUST
}

\author{
中瀬明男* · 木村 孟**. 竹村次朗*** ・ 萩原敏行**** \\ By Akio NAKASE, Tsutomu KIMURA, Jiroh TAKEMURA and Toshiyuki HAGIWARA
}

\begin{abstract}
In order to investigate the bearing capacity of a strip footing on soft clay with a surface crust and the deformations, a series of loading tests was performed. Model clay layers were made by combining consolidation on the lab floor with centrifuge consolidation. Based on observations in the experiments, an upper bound mechanism was proposed. As a result, it was found that the bearing capacity tends to increase with an increase in the strength of the crust and the deformations concentrate along the boundary between the crust and the underlying clay layer. It was also found that the proposed failure mechanism could give a reasonable prediction of the bearing capacity for this type of soils.

Keywords : soft clay, crust, model test, bearing capacity, upper bound
\end{abstract}

\section{1. まえがき}

一般に，正規圧密状態の粘性土地盤では，非排水せん 断強度 $c_{u}$ が深さとともにほぼ直線的に増加する ${ }^{11}$. し かし大陸棚付近の海成粘土地盤の中には, 海水準の変動 や地表面からの乾燥により, 地盤表層部のある深さまで が drying crust ${ }^{2)}$ となっていることが多い.このクラス 卜層内では, 毛管上昇により負圧が生じ, 強度が大きく なっている. その層厚は, 気象条件, 地下水の位置など の要因に依存するが, $4 \mathrm{~m}$ 以内のものがほとんどである. 図一1は,このような地盤の一例としてカナダの Champlain Sea Clay ${ }^{3)}$ の深さ方向の強度分布について LaRochelle の結果の一部を引用したものである. 地盤 表面下約 $2 \mathrm{~m}$ まで $c_{u}$ が深さとともに急激に減少してお り, 地盤表層部の強度分布は, 正規圧密地盤と比べて著 しく異なっている.

また，近年わが国では浅層混合処理工法により，軟弱

* 正会員 工博 東京工業大学教授 工学部土木工学科 ( ₹152 目黒区大岡山 2-12-1)

** 正会員 工博 東京工業大学教授 工学部土木工学科 (同上)

*** 正会員 工修 東京工業大学助手 工学部土木工学科 (同上)

**** 正会員 工修 宇都宮大学助手工学部土木工学科 ( ₹321 宇都宮市石井町 2753)

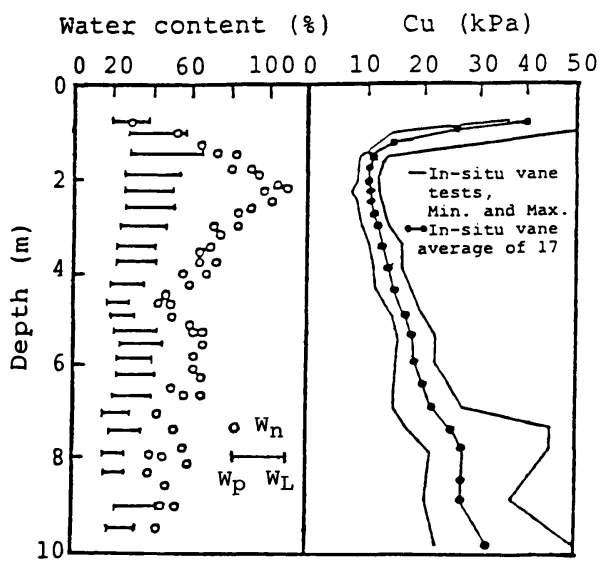

図一1 クラスト地盤の一例 (LaRochelle et al., 1974)

地盤の表層部分を固化する工法が武みられ，その部分の 強度を定量的に評価する必要に迫られている.

このようなクラストを有する地盤の支持力問題につい ての研究は, 二層地盤問題として扱われている. Button ${ }^{4)}$, Chen ${ }^{5)}, \mathrm{Vesic}^{6)}$ らはこの問題を円弧すべり 法により解析し，またPurshothamaraj, P.ら Prandtl-Terzaghi mechanism ${ }^{8)}$ を修正したメカニズム を考えて解析し， $c, \phi, \gamma$ についるとめた二層地盤 
を対象とした支持力図表を示している. Brown and Meyerhof ${ }^{91}$ は, 重力場において強度の異なる二層地盤 上で支持力実験を行い，Buttonの解析值が過大な結果 を与えることを指摘し，その原因を地盤の進行性破壊に あると結論している．しかし，いずれの研究でも地盤の 深さ方向の強度増加は考慮されておらず，実際地盤の問 題を解くまでには至っていない。

近年この種の問題を遠心力載荷装置を用いて実験的に 取り扱抢うとする試みがなされている，わが国では，東 京工業大学のグループによって, 遠心力載荷装置により 正規圧密地盤を作成する手法が開発され，支持力問題， 盛土の安定問題についての一連の実験が行われてい $3^{101.111}$.またケンブリッジ大学においては Davies ${ }^{12} や$ Almeida and Parry ${ }^{13)}$ は，表層部が過圧密でそれ以深は 正規圧密状態となっているような地盤を遠心力載荷装置 を用いて作成し，盛土の安定実験を行っている. 彼らは， まずカオリン粘土の上に Gault clay を置き，重力場に おいて予備圧密を行い，その後遠心力場で圧密するとい う方法で地盤を作成した。しかしこの地盤では，表層の 過圧密部分の地盤の最大強度は表層直下付近の強度と比 較してせいぜい 1.5 倍以内のもので，図一1に例として 示したように実際に経験するような表層強度の大きい場 合についてはまだ試みられていない。

本研究は，実際にみられるような強度の大きいクラス 卜を有する地盤を，重力場における圧密と遠心力場にお ける圧密を組み合わせて作成し，表層のクラスト強度が 地盤の支持力・変形特性に及ぼす影響を検討したものて ある．さらに，実験により得られた破壊形状を参考にし て, 破壊メカニズムを設定した上界値計算ならびに複合 円弧すべり計算を行い，実験結果との比較を行った.

\section{2． 遠心力実験}

\section{（1）応力履歴}

クラストを有する実際の地盤での深さ方向の強度分布 は，表層部が drying crust 状態となっているため，図 一1に示されるような特異な分布形状をしている. 本研 究においてはこのような地盤の第一近似として，図一2 に示すように表層のクラスト内の強度 $c_{u}$ は, 深さとと もに直線的に減少し, クラスト下においては深さととも に $c_{u}$ が直線的に増加する正規圧密状態の強度分布の形 状をもつモデル地盤を考えた。

模型地盤の作成方法 ${ }^{14)}$ は, 以下のような手順で行っ た。まず，表層となるクラスト部分を作成するために重 力場において, 図一3（a）に示すように, 容器の下端 から含水比 $100 \%$ のスラリー状に練り返した粘土試料 を投入し，一層当たり $10 \mathrm{~mm}$ の厚さで 4 層に分けて， 圧密圧力を段階的に減少させて予備圧密を行った。層ご
との圧密を $90 \%$ 圧密終了まで行い，第 4 層目の圧密終 了後, その上に粘土スラリーを置き $19.6 \mathrm{kPa}$ で予備圧. 密を行った。後に示す実験におけるクラスト部分および その下の重力場における予備圧密圧力の値は, 表一1に 示す. 予備圧密終了後試料容器を上下に反転し, 容器の 下端にある予備圧密圧力の大きい部分が地盤表層となる ようにした。その後，クラスト下の正規圧密部分を作成 するために, 遠心力載荷装置により自重圧密を行った。

クラスト部分の強度分布の推定は, 図一4に示すよう な圧密と膨潤による $c_{u}$ の変化の関係 ${ }^{15)}$ を用いて行っ た。

いま予備圧密圧力を $p_{a}^{\prime}$, 遠心圧密終了時における有 効土被り圧を $\sigma_{a}^{\prime}$ とすれば，クラスト部分の強度 $c_{u_{a}}$ は,

$$
c_{u_{a}}=\left(c_{u} / \sigma_{v}^{\prime}\right)_{c} p_{a}^{\prime}-\left(c_{u} / \sigma_{v}^{\prime}\right)_{s}\left(p_{a}^{\prime}-\sigma_{a}^{\prime}\right)
$$

となる。ただし，ここでは地盤の非排水強度増加率 $\left(c_{u} / \sigma_{v}^{\prime}\right)_{c}$ を一定とし, 膨潤に伴う強度減少の割合 $\left(c_{u} / \sigma_{v}^{\prime}\right)_{s}$ も一定であると仮定した。また，クラスト下

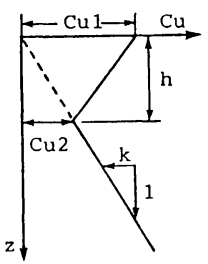

図一2 モデル地盤

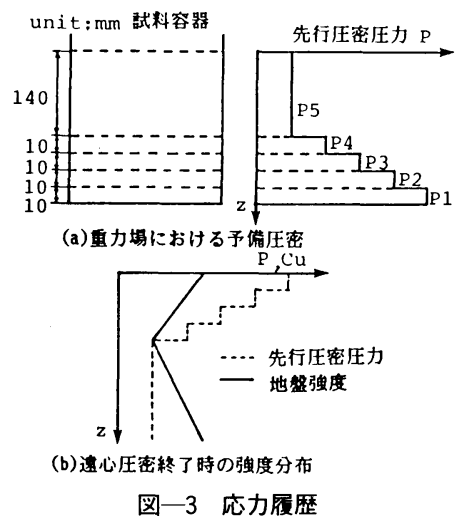

表一1 重力場の予備圧密圧力分布

(単位: $\mathrm{kPa}$ )

\begin{tabular}{|c|c|c|c|c|c|}
\hline & $r-ス a$ & $r-2 b, c$ & $r-2 d, e$ & $r-\lambda f$ & $r-2 g$ \\
\hline 第 1 層P1 & 39.2 & 98.0 & 196.0 & 274.4 & 196.0 \\
\hline 第 2 層P2 & 39.2 & 78.4 & 156.8 & 196.0 & 156.8 \\
\hline 第 3 層P3 & 39.2 & 58.8 & 117.6 & 137.2 & 117.6 \\
\hline 第 4 層P4 & 39.2 & 39.2 & 78.4 & 78.4 & 78.4 \\
\hline 第 5 属P5 & 39.2 & 19.6 & 19.6 & 19.6 & 19.6 \\
\hline
\end{tabular}




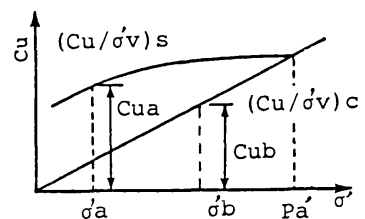

図一4 圧密と膨潤による $c_{u}$ の変化

の正規圧密部分の強度 $c_{u_{b}}$ は, 遠心圧密終了時における 有効土被り圧を $\sigma_{b}^{\prime}$ であるとすると，

$$
c_{u_{b}}=\left(c_{u} / \sigma_{v}^{\prime}\right)_{c} \sigma_{b}^{\prime}
$$

となる. 以上より, 遠心圧密終了時における模型地盤の 各深度における $c_{u}$ の分布形状は，おおむね図一3 ( b ) のようになる，すなわち，地盤の表層のある深さまでは $c_{u}$ が直線的に減少し, それ以深においては $c_{u}$ が直線的 に増加するような分布である.

\section{（2）実験装置および条件}

実験に用いた試料は，塑性指数が 60 の川崎粘土に豊 浦標準砂とこれの砕砂を混合した調整砂（重量比 $2: 1$ の割合で調整）を混入して作成した試料で，これを川崎 粘土Ｍ 20 とよぶものとした．調整砂の M 20 中に占め る混合重量比は約 $60 \%$ である. 表一2 は, 川崎粘土 M 20 の主な物理的性質を示したものである.

また図一5は，同じ試料について行った三軸圧縮試験 結果より得られた $c_{u}$ と, 鉛直有効土被り圧 $\sigma_{v}^{\prime}$ の関係 を示したものである，三軸圧縮試験は，CK $C K_{0}$ 試験と $K_{0}$ 圧密し $K_{0}$ 膨潤した後に行う圧縮試験 $\left(C K_{0} R K_{0} U\right.$ 試 験）を行った。 その結果, 非排水強度増加率 $\left(c_{u} / \sigma_{v}^{\prime}\right)_{c}$ $=0.390$, 膨潤による強度低下率 $\left(c_{u} / \sigma_{v}^{\prime}\right)_{s}=0.127$ が得 られた。.これらの值を式 (1), （2）に代入して, 後に 模型地盤の強度分布を推定した。

図一6は, 試料容器内に載荷システム, 計測器を組み 込んだ載荷時における実験システムの様子を示したもの である. 試料容器の内寸法は, 長さ $500 \mathrm{~mm}$, 幅 $150 \mathrm{~mm}$, 高さ $350 \mathrm{~mm}$ である. 容器本体は剛性構造となっており, 容器正面には観察用の強化ガラスが取り付けられてい る. また, ウォーターポンプグリース ${ }^{16)}$, 容器壁面 に十分に塗り粘土と容器壁面との間に生ずる摩擦を軽減 した.

遠心力場での自重圧密中は, 地盤表面に取り付けた変 位計で地表面の沈下量を，また地盤内に埋め込んだ間隙

\section{表一2 川㥓粘土 M 20 の主な物理的性質}

\begin{tabular}{|l|l|lr|c|}
\hline 液性限界 $($ \% $)$ & 36.2 & 秒 分 & $($ ( ) & 61.7 \\
\hline 塑性限界 $($ ( ) & 16.1 & シルト分 & $($ ( $)$ & 26.1 \\
\hline 塑性指数 & 20.1 & 粘土分 $(<5 \mu)(\%)$ & 12.2 \\
\hline 比 重 & 2.68 & 粘土分 $(<2 \mu)(\%)$ & 8.1 \\
\hline
\end{tabular}

水圧計（Druck 社製）により間隙水圧を計測した．遠心 圧密は各ケースとも約 20 時間行った. 圧密打ち切りの 判断基準は, 時間-表面沈下量関係を $\sqrt{t}$ 法で整理して $90 \%$ 圧密が終了したこと，および間隙水圧が静水圧に 近い值まで消散したことの 2 点によった。

地盤への載荷は, 直流モーターと貫入ジャッキを用い てフーチングを変位制御方式で下降させるという方法で 行った．載荷中は, フーチングに加わる力をロードセル で, 沈下量は変位計で測定した。また，地盤の観測断面 にあらかじめ $15 \mathrm{~mm}$ 間隔に光学ターゲットを格子状に 埋め込み，実験中に写真撮影を行った。

本実験は，平面ひずみ条件で行った，Ko and Davidson ${ }^{17)}$ は砂の支持力実験を行い, 平面ひずみ条件 とするためには中間主応力方向のひずみを $0.1 \%$ 以下 にする必要のあることを報告している. 今回, 容器前面 の強化ガラスの中央部のたわみを両端固定のはりとして 計算すると中間主応力方向に生ずる最大ひずみは 0.07 \%となり, 本実験は平面ひずみ条件を満足しているも のと判断した.

載荷は, 非排水急速載荷となるように載荷速度を 0.1 $\mathrm{mm} / \mathrm{s}$ として行った。載荷用のフーチングは，その底面 が長方形の形状をしたアルミニウム製のものを使い, 粗 な条件となるように厚さ $2 \mathrm{~mm}$ のポーラスストーンを底

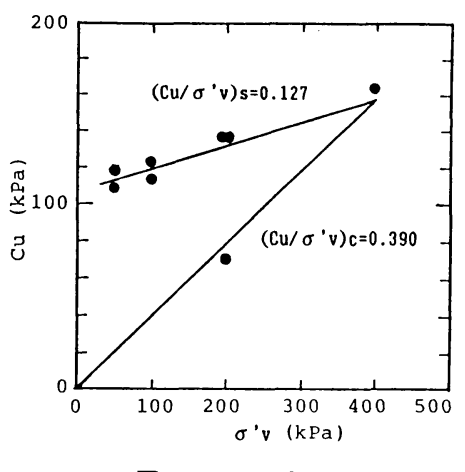

图一5 $\boldsymbol{c}_{\boldsymbol{u}}{ }^{-} \boldsymbol{\sigma}_{v}^{\prime}$ 関係

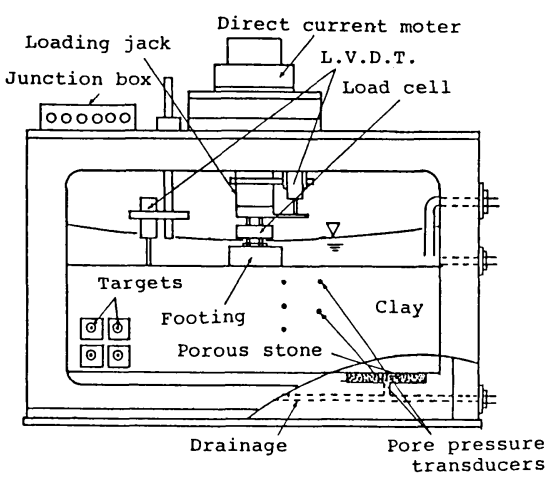

图一6実酫システム 
面に貼り付けた. フーチング幅 $B$ は $50 \mathrm{~mm}$ のものを基 本とし，比較のために $80 \mathrm{~mm}$ のものも用いた。

模型地盤として，図一2に示されるような強度分布を 有するものを想定した．模型地盤の全土層厚は $160 \mathrm{~mm}$ とし $, h=40 \mathrm{~mm}, k=0.323 \mathrm{kPa} / \mathrm{mm}, \quad c_{u 2}=15 \mathrm{kPa}$ で 一定とし, クラスト部分の強度勾配を変化させて実験を 行った. 各実験ケースでの強度比 $c_{u 1} / c_{u 2}$ は, ケース $\mathrm{a}$ が 1 , ケース b, c が 2 , ケース d, e, g が 4, ケース $\mathrm{f}$ が 6 であり，またフーチング幅は，ケース $\mathrm{g}$ が $80 \mathrm{~mm}$ のほかはすべて $50 \mathrm{~mm}$ である. 実験はすべて遠心力加 速度 $100 \mathrm{~g}$ の下で行った. したがって模型はプロトタイ プに換算すると, 表層 $4 \mathrm{~m}$ のクラスト下に厚さ $12 \mathrm{~m}$ 軟 弱層を有する地盤表面に対する, 幅 $5 \mathrm{~m}$ の帯基礎載荷 に相当する.

\section{3. 実験 結果}

\section{（1）地盤強度}

今回作成した地盤は, 重力場において多段階に分けた 予備圧密や試料容器反転のため, 地盤の作成まで圧密除 荷を何回か繰り返し受けている.このため, 地盤の応力 履歴は複雑になっているものと予想される.しかしなが ら, 表層のクラスト部分を過圧密地盤, その下は正規圧 密地盤であると単純化して, 測定した含水比より推定し た地盤の強度分布は，コーン貫入試験結果より得られた 強度分布とほぼ同様の傾向が認められた ${ }^{18)}$.

図一7は, $c_{u 1} / c_{u 2}=4$ の場合について, 図-5の結果 を用いて式（1），（2） より推定した地盤強度の分布を 示したものである.ここで横軸は，各深度における $c_{u}$ 值をその最小值 $c_{u \min }$ で基準化した值を示し, 縦軸は, 各深さを $c_{u \min }$ をとる深さ $z_{\min }$ で基準化した値を示し ている. 図中には, Davies ${ }^{12)}$, Almeida ${ }^{13)}$ の実験結果 も合せて示している. $z / z_{\min }>1$ の部分では, 推定值 において, 推定值はDavies らの結果に比べると, 地表

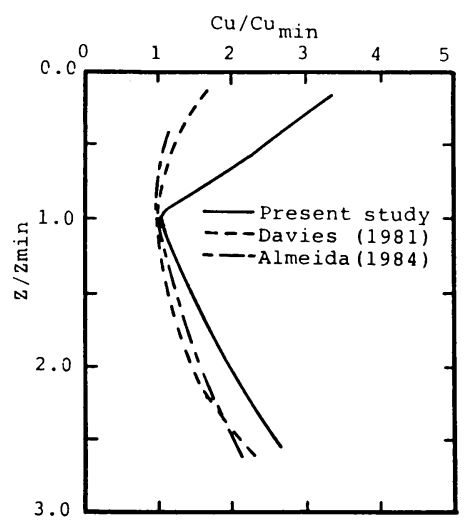

図一7地盤の強度分布
はDavies らの結果とほぼ同様の傾向を示しておりここ の部分において地盤は正規圧密状態となっていることが うかがえる. また， $z / z_{\min }<1$ の地盤表層部分において， 推定值はDavies らの結果に比べると, 地表面近くで 2 倍以上となっている。したがって，本実験による手法に より正規圧密地盤の表層部に大きい強度を有する地盤 が，ほぼ作成されたものと推定される.

ただし，今回の実験は平面ひずみ条件で行ったが，計 算に用いた非排水強度増加率 $\left(c_{u} / \sigma_{v}^{\prime}\right)_{c}$ の值は, $C K_{0} U$ 試験より得られた值 0.390 をそのまま用い, 平面ひずみ に対しての補正は行っていない。 また，実験に用いた試 料川崎粘土 M 20 は塑性指数が 20 と低塑性であるため に，粘土の異方性の影響があると考えられるが，今回の 結果では異方性の影響については考慮していない.

\section{（2）荷重沈下挙動}

図一8は, 載荷実験より得られた荷重強度 $q$ と沈下量 $s$ との関係を示したものである. 極限支持力 $q_{u}$ の決定 は, その曲線に明確なピーク值のあるものはそのピーク 值とし，ケース a のように明確なピークのないものは, 荷重強度 $q$ と沈下量 $s$ を両対数グラフ上に描いた log $p-\log s$ 曲線より決定する De Beer ${ }^{19)}$ の方法を採用し た.ここで，ケース bと $\mathrm{c}$, およびケース $\mathrm{d} と \mathrm{e}$ は地盤 条件を同一として実験を行ったものである，両組ともほ ぼ同様な曲線形状および支持力值を示しており，実験の 再現性は満足できるものと判断した.

$c_{u 1} / c_{u 2}=1$ すなわちクラスト強度がクラスト下端強 度に等しく一定であるケース $\mathrm{a}$ を本実験における基準と して考えると，次のことがわかる．まず， $c_{u 1} / c_{u 2}$ が増 大するにつれてケース $\mathrm{a}$ に比べた $q_{u}$ の值は順次増大し ており, クラストの存在ならびにその強度の増加による 支持力值の増大が認められる. $c_{u 1} / c_{u 2}$ が等しく載荷幅 の異なるケース $\mathrm{d}(B=50 \mathrm{~mm})$ とケース $\mathrm{g}(B=80 \mathrm{~mm})$

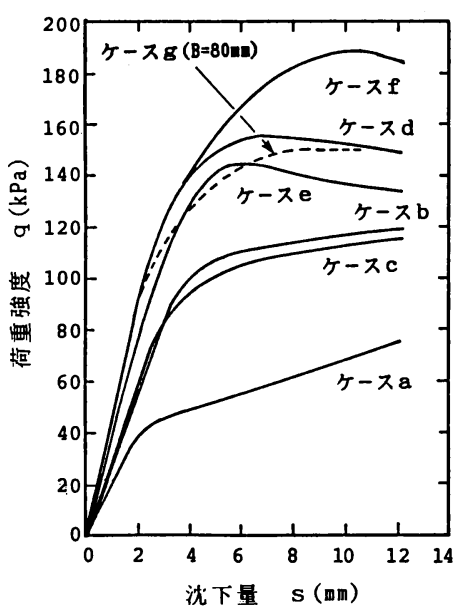

図一8 荷重沈下曲線 

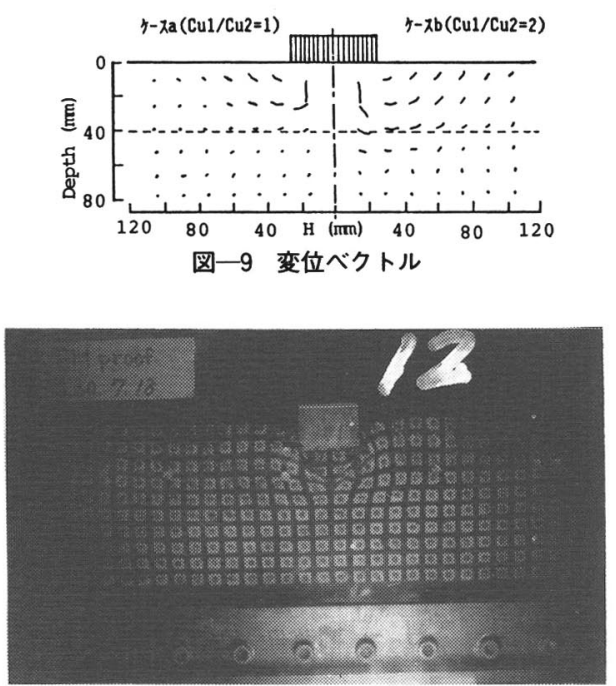

写真一1 破唫時の状況（ケース b)

を比べると，曲線形状および $q_{u}$ の值に大差は認められ ない. また, 曲線形状の特徵として $c_{u 1} / c_{u 2}$ の増加につ れて曲線の初期接線弾性係数が増大し, 曲線のピーク値 も明確に現われている。これらのことより, 表層のクラ ストの強度分布は, 極限支持力に影響を及ぼし, また初 期の曲線形状にも影響を及ぼしているものといえる.

\section{(3) 地盤变 形}

図一9 は，地盤表面に埋め込んだターゲットを載荷中 の写真撮影により追跡することにより得られた，ケース $\mathrm{a}\left(c_{u 1} / c_{u_{2}}=1\right)$ とケース b $\left(c_{u 1} / c_{u 2}=2\right)$ の破壊時にお ける変位ベクトルを示したものである. 写真一1 は, ケー ス bについて $100 \mathrm{~g}$ の遠心力場における載荷後の破壊時 の状況を示したものである. ケース $\mathrm{a}$ の地盤の変形は, 深さ $30 \mathrm{~mm}$ 以内の浅い位置で生じている. ケース $\mathrm{b} て ゙$ は, 変形は深さ $40 \mathrm{~mm}$ 付近において, フーチング中央 部より外側へ向かって水平方向に卓越しており，地盤の 変形領域はケース a よりも広範囲にわたっている. 対象 地盤の強度分布は, 深さ $40 \mathrm{~mm}$ 付近で強度が最弱で急 変している．表層のクラスト強度が大きいケース $\mathrm{b} の$ 変形は, 深い地盤内にまで及んでいる。 また, ケース $\mathrm{d}$, $\mathrm{e}, \mathrm{g}\left(c_{u 1} / c_{u 2}=4\right)$, ケース $\mathrm{f}\left(c_{u 1} / c_{u 2}=6\right)$ の場合にも, クラスト強度が増大するにつれて地盤の変形領域は, ケース a に比べ下方に及んでいるが，クラストを有する 場合には,クラスト下端部において水平方向に卓越した 変形を示す特徵をもつ. 以上より, $c_{u 1} / c_{u 2}$ が 6 程度ま では, 地盤の変形に表層のクラストが大きく影響するこ とがわかる.

\section{4. クラストを有する軟弱地盤の支持力特性}

(1) 計

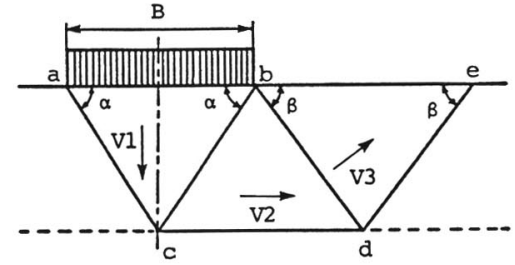

図一10 破壊メカニズム

\section{a) 上界值計算}

実験より観察された破壊形状をもとに破壊メカニズム を図一10に示すように設定し，上界値計算を行った。 すなわち，フーチング直下の主㗢くさび $\mathrm{abc}$ ，水平面に 動く剛体域 bcd および二等辺三角形で表わせた受働領 域 bde で構成されるメカニズムを考えた，最終的な支 持力式 ${ }^{20)}$ を示すと以下のようになる.

$$
\begin{aligned}
\frac{q_{u}}{c_{u 1}} & \leq 2\left(\frac{1}{\sin 2 \alpha}+\frac{1}{\sin 2 \beta}\right)+\frac{c_{u 2}}{c_{u 1}}\left(\frac{1}{\tan \alpha}+\frac{1}{\tan \beta}\right) \\
& -\frac{\left(c_{u 1}-c_{u 2}\right)}{4 c_{u 1}} \frac{B}{h}\left(\frac{2 \tan \alpha}{\sin 2 \beta}+\frac{1}{\cos ^{2} \alpha}\right) \cdots \cdots \cdots \cdots(3) \\
\frac{q_{u}}{c_{u 1}} & \leq \frac{1}{B}\left(\frac{2}{\tan \alpha \cos 2 \beta}+\frac{1}{\sin ^{2} \beta}\right)\left(\left\{2 c_{u 2}+k\left(\frac{B}{2} \tan \alpha\right.\right.\right. \\
& \left.+h)\}\left(\frac{B}{2} \tan \alpha-h\right) / c_{u 1}+8\left(1-\frac{c_{u 1}-c_{u 2}}{h c_{u 1}}\right)\right\}
\end{aligned}
$$

ここで， $\alpha, \beta$ は, メカニズムを最適化するためのパ ラメーターでラジアン単位である. 式（3）は，すべり 線 cd がクラスト内部にある場合, 式 (4) は, すべり 線 $\mathrm{cd}$ がクラスト下にある場合である，計算では，それ ぞれの場合について最小値を求め，そのうちの小さい方 を上界値とした。なお $h$ および $k$ の值は, 実験結果に 対応した值として $h=40 \mathrm{~mm}, k=0.323 \mathrm{kPa} / \mathrm{mm}$ で一 定な值として計算した。

表一 3 に, 各実験ケースについての上界値計算結果を 示した．上界値は，フーチング幅 $B$ が $50 \mathrm{~mm}$ の場合に は, $\alpha=58^{\circ}, B か ゙ ~ 80 \mathrm{~mm}$ の場合には $\alpha=45^{\circ}$ の位置にお

\section{表一3 上界値計算の結果}

\begin{tabular}{|l|c|c|c|}
\hline $\begin{array}{l}\text { TEST } \\
\text { CASE }\end{array}$ & $\begin{array}{c}\alpha \\
\left({ }^{\circ}\right)\end{array}$ & $\begin{array}{c}\beta \\
\left(^{\circ}\right)\end{array}$ & $\begin{array}{c}\text { 上界値 } \\
(\mathrm{kPa})\end{array}$ \\
\hline ケースa & 58.0 & 54.7 & 79.5 \\
\hline ケースb & 58.0 & 52.3 & 109.7 \\
\hline ケースc & 58.0 & 52.3 & 109.7 \\
\hline ケースd & 58.0 & 49.8 & 165.2 \\
\hline ケースe & 58.0 & 49.8 & 165.2 \\
\hline ケースf & 58.0 & 49.8 & 224.9 \\
\hline ケース 8 & 45.0 & 49.8 & 162.8 \\
\hline
\end{tabular}


いて最小値を取っている.これは，いずれも水平方向の すべり線 cd がクラストの下端部分を横切る場合，す なわち $h=(B / 2) \tan \alpha$ の場合に相当する. ケース $\mathrm{a}$ $\left(c_{u 1} / c_{u 2}=1\right)$ を除けば上界值と実験值との差は最大で $20 \%$ 程度という結果を得た。

ケース $\mathrm{a}$ は, 正規圧密地盤に近い地盤形状を有してお り, 今回仮定したメカニズムよりも, Prandtl タイプの メカニズム ${ }^{5)}$ が適当であると考えられる. したがって，

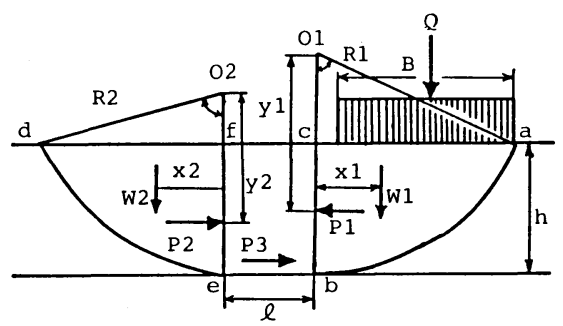

図一11複合円弧すべり計算の破塿メカニズム

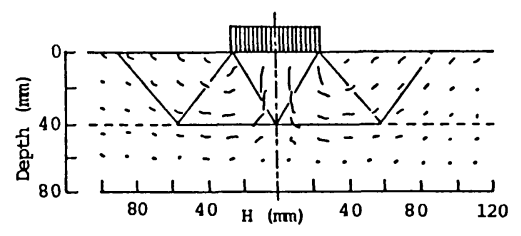

図一12 実験值と計算值の比較

表一4 支持力值の比較

\begin{tabular}{|c|c|c|c|c|}
\hline $\begin{array}{l}\text { TEST } \\
\text { CASE }\end{array}$ & $\mathrm{Cul} / \mathrm{Cu} 2$ & $\begin{array}{l}\text { 実雅值 } \\
(\mathrm{kPa})\end{array}$ & $\begin{array}{l}\text { 上界值 } \\
(\mathrm{kPa})\end{array}$ & $\begin{array}{l}\text { 槙合円䧕 } \\
\text { 解 ( } \mathrm{kPa} \text { ) }\end{array}$ \\
\hline ケースa & 1.0 & 43.0 & 79.5 & 77.6 \\
\hline ケースb & $2.0^{\prime}$ & 109.0 & 109.7 & 106.7 \\
\hline ケースc & 2.0 & 104.0 & 109.7 & 106.7 \\
\hline ケース & 4.0 & 156.0 & 165.2 & 160.2 \\
\hline ケースe & 4.0 & 146.0 & 165.2 & 160.2 \\
\hline ケースf & 6.0 & 189.0 & 224.9 & 215.3 \\
\hline ケース & 4.0 & 150.0 & 162.8 & 155.2 \\
\hline
\end{tabular}

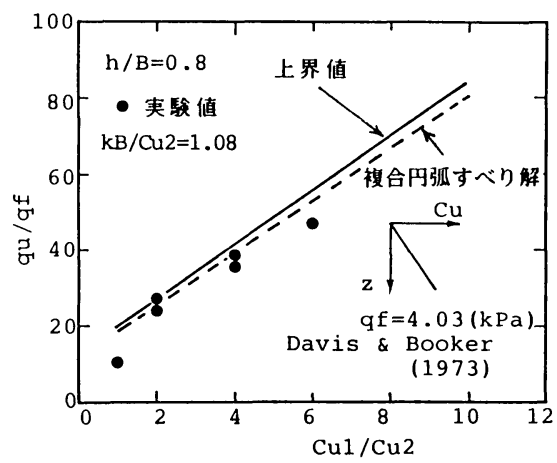

図-13 $\boldsymbol{q}_{u} / \boldsymbol{q}_{f}-c_{u 1} / c_{u 2}$
図一10の破壊メカ二ズムは, $c_{u 1} / c_{u 2}$ が 2 4 程度のク ラストの強度分布を有するものに対して適用できるもの と考えられる.さらに実験により破壊メカニズムを正し く捉えることができるならば，そのメカニズムに従った 上界值計算によってかなり精度のよい推定が行えると考 えている.

b) 複合円弧すべり計算

実験結果ならびに上界值計算結果から, 本実験で対象 とした地盤の破壊特徴として, クラスト下端の強度の最 弱部分において, 水平方向の変位が卓越することがわ かった.そこで実務で使われている円弧すべり法による 解法が，本ケースにも適用できるか否かについて検討し た。

図一11 は，仮定した円弧すべり計算の破壊メカニズ ムを示したものである.このメカニズムは，2つの円弧 と直線によるすべり線を組み合わせた複合円弧すべり 21 を想定したものである. 計算は, 安全率が 1 となる場合 の支持力の最小值を求める方法で行った. 計算結果は図 一13に示すようになり, 最小値は, いずれの場合も水 平方向のすべり線長さ $l$ がゼロの場合にとるという結果 を得た。

\section{（2）実験值との比較}

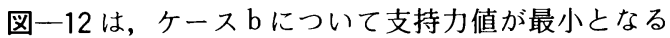
破壊メカニズムを, 破壊時の変位ベクトル上に描いたも のである. 実験の変位ベクトルの向きと上界值計算の破 壊メカニズムの各領域の速度ベクトルの方向はよく一致 しており，また破壊メカニズム外のところでは地盤の変 形は小さい。したがって図一10の破壊メカニズムは, 実験で観察された地盤の変形性状を精度よく捉えている といえよう.

表一4 および図一13 は, $c_{u 1} / c_{u 2}$ の違いによる支持力 值の変化についてまとめたものである，図の縦軸は，実 験および解析より得られた支持力值 $q_{u}$ をDavis and Booker ${ }^{22)}$ により与えられた地表面の $c_{u}$ がゼロの正規 圧密地盤の厳密解 $q_{s}$ で基準化したものである. $c_{u 1} / c_{u 2}$ が 4 以内までの範囲では，上界值および複合円弧すべり 法による計算結果と実験結果は，ほぼ一致した傾向を示 しており，この範囲内ではクラストを有する地盤の支持 力は, 計算結果から予測することができるものと考えら れる.

しかしながら $c_{u 1} / c_{u 2}$ が 6 以上となると，計算結果は 実験值を過大に評価している傾向がみられる．これは， 実験では $c_{u 1} / c_{u 2}$ が大きくなるにつれて，地盤の破壊領 域が深さ方向に拡大する傾向が現われて, 破壊メカ二ズ ムが異なってくるためと思われる. 上界値と実験值の差 が， $c_{u 1} / c_{u 2}$ の増大につれて大きくなるのはこのためと 考えられる. また $c_{u 1} / c_{u 2}$ が 1 の場合には, 計算值は実 


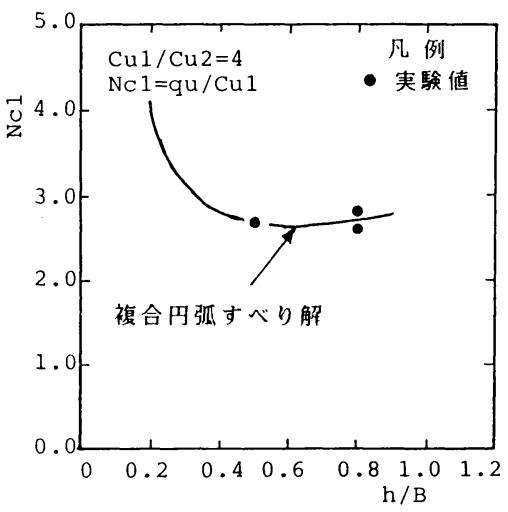

図-14 $N_{c 1}\left(q_{u} / c_{u 1}\right)-h / B$

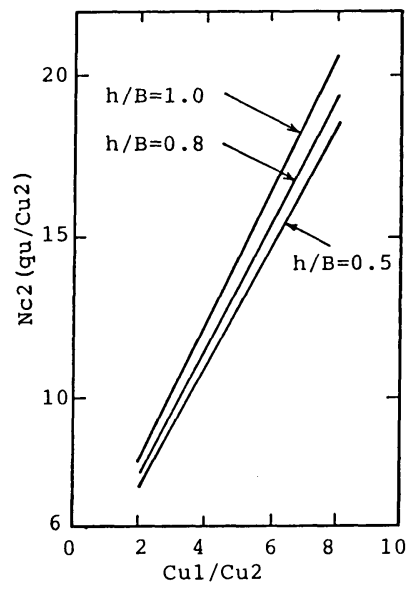

図-15 $\boldsymbol{N}_{c 2}\left(\boldsymbol{q}_{u} / \boldsymbol{c}_{u 2}\right)-\boldsymbol{c}_{u 1} / \boldsymbol{c}_{u 2}$

験値の約 2 倍の值を取っている.これは，解析ではクラ スト内の強度を $c_{u 2}$ で一定として計算しているが，実験 では地表面付近では厳密には強度は $c_{u 2}$ ではなく，膨潤 による影響を受けてそれより小さい値となっているため と思われる.

図一13は $h / B=0.8$ という条件での $c_{u 1} / c_{u 2}$ に対す る支持力の変化を示した結果であり，図一14には， $c_{u 1} / c_{u 2}$ が 4 の場合の $h / B$ と支持力係数 $N_{c 1}\left(q_{u} / c_{u 1}\right)$ の関係を実験值と計算値の双方について示した．図中の 実線は，複合円弧すべり計算より得られた結果を示して いる. 計算結果によれば， $N_{c 1}$ の值は $h / B$ が 0.4 程度 以下になると急激に増大し，また $h / B$ が 0.9 を超える とやや増加する傾向がある。しかしながら， $h / B$ が 0.5 から 0.8 の範囲では $N_{c 1}$ は $h / B$ の值によらないという 結果となっており，この範聿では図一13の結果を用い てもよいといえよう.

図一15 は, $h / B$ が $0.5 ， 0.8 ， 1.0$ における $c_{u 1} / c_{u 2}$ と支持力係数 $N_{\mathrm{c} 2}\left(q_{u} / c_{u 2}\right)$ の関係を複合円弧すべり計 算により求めたものである.ここで, 例題として図一1
のような強度分布を有する地盤の支持力值について考え てみる. 図一1 から, $c_{u 1}=40(\mathrm{kPa}), c_{u 2}=10(\mathrm{kPa})$, $h=2(\mathrm{~m})$ と読み取ることができる. もしも $B$ が $4 \mathrm{~m}$ であるならば $h / B=0.5$ となり, 図一15 から $c_{u 1} / c_{u 2}=$ 4 におけるこのときの $N_{\mathrm{c} 2}$ の值は 10.6 と求まる. よっ て地盤の支持力値 $q$ は $q=10.6 \times 10=106(\mathrm{kPa})$ となる. 一方，表層部のクラスト部分の強度を無視した正規圧密 地盤の支持力値を Davis and Booker の式より推定する 之約 $1 / 5$ の $q=23(\mathrm{kPa})$ が得られ, クラスト部分の支 持力への寄与が大きいことがわかる.

\section{5. 結 論}

今回行ったクラストを有する粘性土地盤についての支 持力実験ならびに解析結果より, 以下のことが知られた.

（1）遠心力載荷装置を用いた圧密による今回の手法 により, Almeidaの作成した地盤と比べて，より強い 強度を地盤表層部に有するような粘性土地盤を，実験室 内において作成することができた。

（2）クラストを有する地盤の変形挙動は，正規圧密 地盤とは異なる。すなわち, 変形は主にクラスト内で発 生し, 特にクラスト下端において水平方向変位が卓越す る.

（3）観測された地盤変形に基づいて設定した破壊メ カニズムに対して上界值計算を行った結果，実測された 極限支持力值を $20 \%$ 以内の精度で予測することができ た.

(4) $h / B$ が $0.5 \sim 0.8$ の範囲であれば， $c_{u 1} / c_{u 2}$ が 4 以下のクラストを有する粘性土地盤の支持力値は，本 論文で示した上界值計算または複合円弧法で推定してよ いようである.

\section{参 考文 献}

1) Nakase, A. : Bearing capacity of retangular footings on clay of strength increasing linearly with depth, Soils and Foundations, Vol.21, No.4, pp.101 108, 1981.

2) Terzaghi, K. : Influence of geological factors on the engineering properties of sediments, Economic Geology, 50, pp. 557 618, 1955.

3) LaRochelle, P., Trak, B., Tavenas, F. and Roy, M. : Failure of a test embankment on a sensitive Champlain clay deposit, Canadian Geotechnical Journal, Vol.11, pp. 142 164, 1974.

4) Button, S. J. : The Bearing Capacity of Footing on a Two-Layer Cohesive Subsoil, Proc. 3 rd International Conference Soil Mechanics Foundation Engineering, Vol. 1, pp. 332 335, 1953.

5) Chen, W. F. : Limit Analysis and Soil Plasticity, Elseveir Scientific Publishing Company, 1975.

6) Vesic, A.S. : Bearing Capacity of Shallow Foundations, in Foundation Engineering Handbook, Winter- 
korn and Fang, eds, Van Nostrand Reinhold Company, New York, N. Y., 1975.

7) Purushothamaraj, P., Ramiah, B. K. and Rao, K. N. V. : Bearing Capacity of Strip Footings in Two Layered Cohesive-friction Soils, Canadian Geotechnical Journal, Vol.11, pp. 32 45, 1974.

8) Terzaghi, K. : Theoretical soil mechanics, John Wiley and Sons, New York, N. Y., 1948.

9) Brown, J. D. and Meyerhof, G. G. : Experimental study of bearing capacity in layered clays, Proc. 7 th International Conference Soil Mechanics Foundation Engineering, pp. 45 51, 1969 .

10) Kimura, T., Kusakabe, O., Takemura, J. and Saitoh, K. : Preparation of a normally consolidated clay stratum in a centrifuge, Soils and Foundations, Vol.24, No.4, pp. $71 \sim 83,1984$.

11) Nakase, A., Kusakabe, O. and Wong, S. F. : Centrifuge Model Tests on Bearing Capacity of Clay, Geotechnical Journal, Vol.110, pp. 1749 1765, 1984.

12) Davies, M.C.R. : Centrifuge modelling of embankments on clay foundations, Ph. D. thesis, University of Cambridge, 1981.

13) Almeida, M.S.S. and Parry, R. H. G. : Penetrometer apparatus for use in the centrifuge during flight, Proc. Symposium on the application of centrifuge modelling to Geotechnical Design, pp. 47 64, 1984.

14) Nakase, A., Kimura, T., Saitoh, K., Takemura, J. and Hagiwara, T. : Behaviour of soft clay with a surface crust Proc. 8 th Asian Regional Conference on SMFE, 1987. (to appear)

15）中瀬明男・小林正樹・勝野 克：圧密および膨張による 飽和粘土のせん断強度の変化, 港湾技術研究所報告, Vol. 8, No. 4, pp. 103 143, 1969.

16) Mair, R. J. : Centrifugal Modelling of Tunnel Construction in Soft Clay, Ph. D. thesis, University of Cambridge, 1979.

17) Ko, H. Y. and Davidson, L. W. : Bearing Capacities of Footings in Plane Strain, Proc. ASCE, Vol.99, No. SM 1, pp. 1 23, 1973.

18）池田直太・萩原敏行・斉藤邦夫・木村 孟：クラストを 有する正規圧密地盤の作成, 第 21 回土質工学研究発表会, pp. 1190 1120, 1986.

19) De Beer, E.E. : Experimental Determination of the Shape Factors and the Bearing Capacity Factors of Sand, Geotechnique, Vol.20, No.4, pp. $387 \sim 441$, 1970.

20）萩原敏行：クラストを有する粘性土地盤の支持力・変形 に関する研究，東京工業大学修士論文， 1986.

21）土質工学会編，土質工学ハンドブック，pp. 241， 1982.

22) Davis, E.H. and Booker, J.R. : The effect of increasing strength with depth on the bearing capacity of clays, Geotechnique, Vol.23, No.4, pp. 551 563, 1973.

(1986.12.5 • 受付) 